\title{
Conversion to full sternotomy during minimal-access cardiac surgery: Reasons and results during a 9.5-year experience
}

Minoru Tabata, MD, Ramanan Umakanthan, MD, Zain Khalpey, MD, PhD, Sary F. Aranki, MD, Gregory S. Couper, MD, Lawrence H. Cohn, MD, and Prem S. Shekar, MD

Objective: A hemisternotomy approach to minimal-access cardiac surgery is associated with a faster postoperative recovery because of reduced postoperative pain and improved respiratory function. Conversion to a full sternotomy is occasionally required for reasons that remain inadequately reported.

Methods: Between January 1996 and June 2005, 907 cardiac surgical patients were planned for an upper hemisternotomy and 528 for a lower hemisternotomy. We retrospectively reviewed 45 patients who required conversion to a full sternotomy.

Results: Twenty-four (2.6\%) of 907 patients required a conversion from upper hemisternotomy because of bleeding $(\mathrm{n}=8)$, ventricular dysfunction $(\mathrm{n}=5)$, refractory ventricular arrhythmia $(n=3)$, poor exposure $(n=2)$, and other causes $(n=6)$. Eight $(33.3 \%)$ of 24 patients died perioperatively. Of the 883 patients who went on to have an operation through the upper hemisternotomy approach, the mortality was $1.7 \%$ (15/883). Twenty-one (4.0\%) of 528 patients required conversion from a lower hemisternotomy because of poor exposure $(\mathrm{n}=16)$, bleeding $(\mathrm{n}=1)$, refractory ventricular arrhythmia $(\mathrm{n}=3)$, and a retained venous cannula $(n=1)$. None of these patients died postoperatively. Of the 507 patients who went on to have an operation through the lower hemisternotomy approach, the mortality was $1.2 \%(6 / 507)$.

Conclusion: Conversion to a full sternotomy occurs infrequently during minimalaccess cardiac surgery. Upper hemisternotomy conversions are usually urgent after crossclamp removal and are often associated with serious morbidity and mortality. Conversely, lower hemisternotomy conversions are performed electively in the prebypass period because of poor exposure and are not associated with complications.

From the Division of Cardiac Surgery, Brigham and Women's Hospital, Boston, Mass.

Received for publication Oct 3, 2006; revisions received Jan 14, 2007; accepted for publication Jan 23, 2007.

Address for reprints: Prem Shekar, MD, Division of Cardiac Surgery, Brigham and Women's Hospital, 75 Francis St, Boston, MA 02446 (E-mail: pshekar@partners.org).

J Thorac Cardiovasc Surg 2007;134:165-9

$0022-5223 / \$ 32.00$

Copyright $(9) 2007$ by The American Association for Thoracic Surgery

doi:10.1016/j.jtcvs.2007.01.077
M inimal-access cardiac surgery was introduced in the $1990 \mathrm{~s}^{1,2}$ and is becoming an accepted procedure. Minimal-access cardiac surgery reduces surgical invasiveness, increases patient satisfaction, and is a better use of health care resources. Studies have shown that minimal-access cardiac surgery is associated with a shorter length of hospital stay, earlier extubation, and less blood loss or less blood transfusion requirement compared with conventional cardiac surgery. ${ }^{2-7}$

An upper hemisternotomy is the most common minimal-access approach for aortic valve, ascending aortic, arch, and root surgery. This approach can also be used for subaortic myectomy and mitral valve and tricuspid valve surgery. Lower hemisternotomy is another useful approach for mitral valve surgery, tricuspid valve surgery, and a few other cardiac operations. In the vast majority of patients, these approaches lead to the successful performance of the planned surgical procedure. 


\section{Abbreviation and Acronym \\ $\mathrm{CPB}=$ cardiopulmonary bypass}

Occasionally, conversion to a full sternotomy is required for reasons that have not been well investigated or reported yet.

Our group performs an upper hemisternotomy for aortic valve, ascending aortic, arch, root, and subaortic surgery. A lower hemisternotomy is done for mitral valve surgery, tricuspid valve surgery, excision of left atrial myxomas, atrial septal defect repair, and patent foramen ovale repair. We retrospectively reviewed the intraoperative rationale for converting from an upper or lower hemisternotomy to a full sternotomy during our 9.5-year experience.

\section{Materials and Methods \\ Patient Data}

Between January 1996 and June 2005, 907 cardiac surgical patients were planned for an upper hemisternotomy and 528 for a lower hemisternotomy. We retrospectively reviewed 45 patients who required conversion to a full sternotomy. Our definition for a conversion in this series was any intraoperative conversion from a partial sternotomy to a full sternotomy. All preoperative data, in-hospital outcomes, and postdischarge outcomes were collected from patient medical records and the Brigham and Women's Hospital cardiac surgery database according to The Society of Thoracic Surgeons definitions. This study was approved by the institutional review board of Brigham and Women's Hospital (protocol no. 2005-P-001686). Values of continuous variables are expressed as means \pm standard deviations.

\section{Surgical Procedure}

All patients receive external defibrillator pads and undergo a transesophageal echocardiogram in the operating room.

An upper hemisternotomy incision is 6 to $8 \mathrm{~cm}$ long. The sternum is divided from the sternal notch down to the level of the fourth intercostal space with a regular sternal saw and then extended toward the right fourth intercostal space with an oscillating saw. Three retraction stitches are placed on the right edge of the pericardium and 1 at the top left corner. These are anchored to the subcutaneous tissue. Cardiopulmonary bypass (CPB) is established by means of direct ascending aortic or peripheral arterial cannulation and percutaneous femoral venous or direct right atrial cannulation. A retrograde cardioplegia cannula is placed into the coronary sinus through the right atrial appendage with the guidance of transesophageal echocardiography. A left ventricular vent is placed through the right superior pulmonary vein, when necessary. This approach is also used in reoperative surgery. ${ }^{8}$

A lower hemisternotomy incision is also 6 to $8 \mathrm{~cm}$ long. The sternum is divided from the base of the xiphoid process up to the level of the second intercostal space with the regular sternal saw and then extended toward the right second intercostal space with an oscillating saw. Three retraction stitches are placed on the right edge of the pericardium and 1 at the top left corner. These are anchored to the subcutaneous tissue. Both top stitches are placed near the pericardial reflection for better exposure of the aorta; the other 2 stitches on the right pericardium are placed deep for better exposure of the mitral valve. CPB is established by means of direct ascending aortic cannulation and percutaneous femoral venous or direct bicaval cannulation. This approach is not used for reoperative surgery.

All procedures were performed without endoscopic or robotic assistance. Our detailed strategies for minimal-access cardiac surgery have been published before. ${ }^{3}$

\section{Results}

\section{Conversion From Upper Hemisternotomy}

Twenty-four (2.6\%) of 907 patients required conversion from an upper hemisternotomy (group US). These patients were converted because of bleeding $(n=8)$, ventricular dysfunction $(\mathrm{n}=5)$, refractory ventricular arrhythmia $(\mathrm{n}=3)$, poor exposure $(\mathrm{n}=2)$, epicardial pacing wire placement in reoperative surgery $(n=1)$, a protamine reaction $(n=1)$, intraoperative change in the operative plan $(\mathrm{n}=1)$, paravalvular leak $(\mathrm{n}=1)$, undiagnosed pericarditis requiring pericardiectomy $(\mathrm{n}=1)$, and pericardial clot evacuation $(n=1)$. Patient characteristics, diagnoses, performed procedures, and reasons for conversion in group US are shown in Table 1.

\section{Conversion From Lower Hemisternotomy}

Twenty-one $(4.0 \%)$ of 528 patients required conversion from a lower hemisternotomy (group LS). These patients were converted because of poor exposure $(n=16)$, bleeding $(\mathrm{n}=1)$, refractory ventricular arrhythmia $(\mathrm{n}=3)$, and a retained venous cannula $(\mathrm{n}=1)$. Patient characteristics, diagnoses, performed procedures, and reasons for conversion in group LS are shown in Table 2.

\section{Operative Outcome}

Of the 883 patients who went on to have their operations through the upper hemisternotomy, the mortality rate was $1.7 \%(15 / 883)$. However, $8(33.3 \%)$ of 24 patients in group US (who were converted to a full sternotomy) died perioperatively. Four of them were converted for ventricular dysfunction, 2 for bleeding, and 1 each for epicardial pacing wire placement and pericardial clot evacuation. Three (12\%) patients had reoperations for bleeding, and $4(16 \%)$ patients had deep sternal wound infections.

Of the 507 patients who went on to have their operations through the lower hemisternotomy, the mortality rate was $1.2 \%(6 / 507)$. None of the patients in group LS (who were converted to full sternotomy) died postoperatively. One (4.5\%) patient had a sterile sternal dehiscence. There were no other complications in this group.

\section{Discussion}

This is the first documented report of conversions from partial sternotomy to full sternotomy in minimal-access cardiac sur- 
TABLE 1. Conversions from upper hemisternotomy to full sternotomy

\begin{tabular}{|c|c|c|c|c|c|}
\hline Patient no. & Age (y) & Sex & Diagnosis & Primary procedure & Reason for conversion \\
\hline 1 & 86 & $\mathrm{M}$ & AS & AVR & $\begin{array}{l}\text { Coronary sinus perforation during placement } \\
\text { of retrograde cardioplegia cannula }\end{array}$ \\
\hline 2 & 73 & $\mathrm{~F}$ & $\mathrm{AS}, \mathrm{Al}$ & AVR & $\begin{array}{l}\text { Coronary sinus perforation during placement } \\
\text { of retrograde cardioplegia cannula }\end{array}$ \\
\hline 3 & 82 & $\mathrm{~F}$ & AS & AVR & $\begin{array}{l}\text { RA perforation during placement of } \\
\text { retrograde cardioplegia cannula }\end{array}$ \\
\hline 4 & 85 & $\mathrm{~F}$ & AS & AVR & $\begin{array}{l}\text { Bleeding from RAA cannulation site after } \\
\text { decannulation }\end{array}$ \\
\hline 5 & 89 & M & $\begin{array}{l}\text { AS, s/p CABG, patent } \\
\text { LITA and vein grafts }\end{array}$ & Reoperative AVR & RV tear from pacing wire \\
\hline 6 & 81 & $\mathrm{~F}$ & AS & AVR & RV tear from pacing wire \\
\hline 7 & 69 & $\mathrm{~F}$ & AS & AVR & $\begin{array}{l}\text { Hypotension caused by bleeding from } \\
\text { femoral arterial catheterization site }\end{array}$ \\
\hline 8 & 60 & $\mathrm{~F}$ & AS, TR & AVR, TVP & $\begin{array}{l}\text { Hypotension caused by iliac vein laceration } \\
\text { from percutaneous venous cannulation }\end{array}$ \\
\hline 9 & 75 & $\mathrm{~F}$ & AS & AVR & $\begin{array}{l}\text { RV failure requiring } C A B G \text { to the right } \\
\text { coronary artery }\end{array}$ \\
\hline 10 & 60 & $\mathrm{~F}$ & AS & AVR & LV failure requiring LVAD implantation \\
\hline 11 & 73 & $\mathrm{M}$ & $\begin{array}{l}\text { AS, s/p CABG, patent } \\
\text { LITA and vein grafts }\end{array}$ & Reoperative AVR & $\begin{array}{l}\text { RV failure requiring } C A B G \text { to the right } \\
\text { coronary artery }\end{array}$ \\
\hline 12 & 69 & $\mathrm{~F}$ & AS & AVR & $\begin{array}{l}\text { LV failure requiring second CPB run after } \\
\text { decannulation and IABP }\end{array}$ \\
\hline 13 & 54 & $\mathrm{M}$ & $\begin{array}{l}\text { Al, ascending aortic } \\
\text { aneurysm }\end{array}$ & $\begin{array}{l}\text { Aortic root replacement } \\
\text { (composite valve graft) }\end{array}$ & $\begin{array}{l}\text { Biventricular failure requiring CABG and } \\
\text { then BIVAD implantation }\end{array}$ \\
\hline 14 & 68 & $\mathrm{~F}$ & AS & AVR & Refractory VF requiring internal defibrillation \\
\hline 15 & 84 & $\mathrm{M}$ & $\begin{array}{l}\text { AS, s/p CABG, patent } \\
\text { LITA and vein grafts }\end{array}$ & Reoperative AVR & Refractory VF requiring internal defibrillation \\
\hline 16 & 73 & $\mathrm{~F}$ & AS & $\begin{array}{l}\text { Aortic root replacement (stentless } \\
\text { bioprosthetic valve) }\end{array}$ & Refractory VF requiring internal defibrillation \\
\hline 17 & 78 & M & $\begin{array}{l}\text { AS, s/p CABG, patent } \\
\text { LITA and vein grafts }\end{array}$ & Reoperative AVR & Poor exposure of aortic valve \\
\hline 18 & 65 & M & AS & AVR & Poor exposure of aortic valve \\
\hline 19 & 81 & $\mathrm{~F}$ & Aortic arch aneurysm & $\begin{array}{l}\text { Reoperative patch repair of arch } \\
\text { aneurysm }\end{array}$ & $\begin{array}{l}\text { Failure of transvenous pacing requiring } \\
\text { epicardial pacing wire }\end{array}$ \\
\hline 20 & 67 & $F$ & AS & AVR & $\begin{array}{l}\text { Hypotension after protamine reaction } \\
\text { requiring second CPB run }\end{array}$ \\
\hline 21 & 67 & $F$ & AS & $\begin{array}{l}\text { Aortic root replacement (stentless } \\
\text { bioprosthetic valve) }\end{array}$ & $\begin{array}{l}\text { Change in procedure from mechanical valve } \\
\text { implantation to stentless bioprosthetic } \\
\text { valve }\end{array}$ \\
\hline 22 & 88 & $M$ & AS & AVR & $\begin{array}{l}\text { Perivalvular leak requiring repeat CPB run, } \\
3 \text { times }\end{array}$ \\
\hline 23 & 85 & $F$ & AS & AVR & $\begin{array}{l}\text { Requirement of pericardiectomy for CPB } \\
\text { wean }\end{array}$ \\
\hline 24 & 77 & $\mathrm{~F}$ & AS & AVR & $\begin{array}{l}\text { Old clot in the pericardial space requiring } \\
\text { exploration }\end{array}$ \\
\hline
\end{tabular}

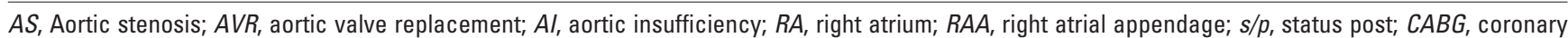
artery bypass grafting; $L I T A$, left internal thoracic artery; $S V G$, saphenous vein graft; $R V$, right ventricle; $T R$, tricuspid regurgitation; TVP, tricuspid valve repair; $L V$, left ventricle; $L V A D$, left ventricular assist device; $C P B$, cardiopulmonary bypass; $B I V A D$, biventricular assist device; $V F$, ventricular fibrillation.

gery. An upper hemisternotomy has been shown to be a safe and effective approach. ${ }^{3-7}$ A lower hemisternotomy has not been reported as often as an upper hemisternotomy; however, Greelish and colleagues ${ }^{9}$ have demonstrated excellent outcomes in a series of minimally invasive mitral valve repairs using this approach. Doty and associates ${ }^{10}$ have reported 112 cases of valve surgery with a lower hemisternotomy approach, including double- and triple-valve operations.

In our series the incidence of converting an upper hemisternotomy was $2.6 \%$, which is low and comparable with a 
Table 2. Conversions from lower hemisternotomy to full sternotomy

\begin{tabular}{|c|c|c|c|c|c|}
\hline Patient no. & Age (y) & Sex & Diagnosis & Primary procedure & Reason for conversion \\
\hline 1 & 48 & $\mathrm{~F}$ & MS, MR, PFO & MVP, PFO & Poor exposure of aorta \\
\hline 2 & 69 & $\mathrm{M}$ & MR & MVP & Poor exposure of aorta \\
\hline 3 & 73 & $\mathrm{M}$ & MR, mitral valve endocarditis & MVP & Poor exposure of aorta \\
\hline 4 & 56 & $\mathrm{~F}$ & MR, TR & MVP, TVP & Poor exposure of aorta (severe scoliosis) \\
\hline 5 & 54 & $\mathrm{~F}$ & MR & MVP & Poor exposure of aorta (pericardial adhesions) \\
\hline 6 & 65 & $\mathrm{M}$ & MR, TR, RA tumor & $\begin{array}{l}\text { MVP, TVP, RA } \\
\text { tumor resection }\end{array}$ & Poor exposure of aorta (pericardial adhesions) \\
\hline 7 & 69 & $\mathrm{~F}$ & MR, ASD & MVP, ASD & Poor exposure of mitral valve \\
\hline 8 & 41 & $\mathrm{M}$ & MR & MVP & Poor exposure of mitral valve \\
\hline 9 & 41 & $\mathrm{M}$ & MR & MVP & Poor exposure of mitral valve \\
\hline 10 & 47 & $\mathrm{M}$ & MR, TR, PFO & MVP, TVP, PFO & Poor exposure of mitral valve \\
\hline 11 & 47 & $\mathrm{M}$ & ASD & ASD & Poor exposure of mitral valve \\
\hline 12 & 39 & $\mathrm{M}$ & MR & MVP & Poor exposure of mitral valve \\
\hline 13 & 85 & $\mathrm{~F}$ & $\mathrm{MR}$ & MVP & Poor exposure of mitral valve \\
\hline 14 & 45 & $\mathrm{M}$ & $\mathrm{MR}$ & MVP & Poor exposure of mitral valve \\
\hline 15 & 42 & $\mathrm{~F}$ & MR & MVP & Poor exposure of mitral valve \\
\hline 16 & 37 & $\mathrm{~F}$ & $\mathrm{MR}$ & MVP & Poor exposure of mitral valve \\
\hline 17 & 63 & $\mathrm{~F}$ & MR & MVP & Refractory VF requiring internal defibrillation \\
\hline 18 & 44 & M & MR & MVP & $\begin{array}{l}\text { Refractory VF requiring internal defibrillation } \\
\text { and IABP }\end{array}$ \\
\hline 19 & 44 & $\mathrm{M}$ & MR, PFO & MVP, PFO & Refractory VF requiring internal defibrillation \\
\hline 20 & 53 & $\mathrm{M}$ & MR & MVP & $\begin{array}{l}\text { Retention of femoral venous cannula requiring } \\
\text { second CPB run }\end{array}$ \\
\hline 21 & 70 & $F$ & MR & MVP & $\begin{array}{l}\text { SVC perforation from internal jugular venous } \\
\text { cannula }\end{array}$ \\
\hline
\end{tabular}

$\overline{M S}$, Mitral stenosis; $M R$, mitral regurgitation; $P F O$, patent foramen ovale; $M V P$, mitral valve repair; $T R$, tricuspid regurgitation; TVP, tricuspid valve repair; $R A$, right atrium; $A S D$, atrial septal defect; $V F$, ventricular fibrillation; $I A B P$, intra-aortic balloon pump; $C P B$, cardiopulmonary bypass; $S V C$, superior vena cava.

previously reported study's conversion rate of $2.4 \% .^{11}$ Intriguingly, conversion because of poor exposure was necessary in only $2(0.2 \%)$ patients. The upper hemisternotomy provides excellent exposure of the aortic valve, root, ascending aorta, and arch.

Bleeding was the most common indication for conversion from the upper hemisternotomy. We recommend attention to the following technical details to avoid such a problem. A retrograde cardioplegia cannula can be placed through the right atrial appendage with transesophageal echocardiographic guidance; however, it is more difficult through an upper hemisternotomy than a full sternotomy. As a consequence, we recommend that should there be any difficulty in placing a retrograde cardioplegia cannula (particularly in elderly patients with friable tissues), the placement should be aborted or deferred until after an elective conversion to a full sternotomy. Temporary ventricular pacing wire placement on the anterior or inferior surface of the right ventricle is challenging in the upper hemisternotomy approach. We recommend that this maneuver be done very carefully on a decompressed heart during CPB. Alternatively, pulmonary arterial catheters with pacing capabilities can also be used, especially in reoperative minimal-access surgery through an upper hemisternotomy, where exposure of the right ventricular free wall can be difficult.

Ventricular dysfunction was the next most common indication for conversion from an upper hemisternotomy. In the 2 patients with right heart failure, hemodynamics improved after bypass grafting to the right coronary system that was previously deemed unnecessary. One patient with left ventricular dysfunction was salvaged after additional rest on CPB and the insertion of an intra-aortic balloon pump. One patient each with left and biventricular failure required a left and biventricular assist device, respectively. Although myocardial protection techniques were the same in these patients as with the full sternotomy approach, ventricular dysfunction resulted because of unclear reasons. We cannot emphasize enough the importance of good myocardial protection. We use a combination of antegrade, retrograde, and direct coronary cold blood cardioplegia at $8^{\circ} \mathrm{C}$ administered every 20 minutes.

Appropriate and accurate positioning of external defibrillator pads is important. Occasionally, pediatric defibrillator paddles can be introduced through an upper hemisternotomy incision. In all patients with refractory ventricular fibrillation, successful cardioversion was achieved after conversion. 
The lower hemisternotomy conversion rate was $4.0 \%$ (21/528). To our knowledge, there have not been any reports of conversions to full sternotomy from a lower hemisternotomy in the literature. The most common reason for a conversion was poor exposure of the aorta or the mitral valve $(\mathrm{n}=16)$. Although conversion is recommended in these cases, axillary or femoral cannulation might be another option ${ }^{12}$ when the aorta is not well visualized. Generally, obesity, deep chests, and small left atria make exposure challenging through this approach. In such patients we now perform a full sternotomy with a smaller skin incision. The shape of the thorax (eg, the depth of the thorax and the length of the sternum), anteroposterior and lateral views of a chest radiograph, and an echocardiogram need to be carefully examined before determining the incision. To reiterate, after a partial sternotomy, pericardial traction stitches are critical in providing a good exposure for the surgeon.

Once again, as with the upper hemisternotomy approach, appropriate and accurate positioning of the external defibrillator pads is important. Occasionally, pediatric defibrillator paddles can be introduced through a lower hemisternotomy incision.

One patient was converted to a full sternotomy after perforation of the superior vena cava during insertion of a percutaneous venous cannula through the right internal jugular vein. We have now abandoned this technique. When the venous drainage is inadequate with a percutaneous femoral venous cannula, an additional cannula is directly placed into the superior vena cava through the incision.

In group LS operative mortality was zero. One patient had a sterile sternal dehiscence. There were no other complications.

It is difficult to determine predictors of conversion in this series because there is a spectrum of causes for conversion, and the number in each category is too small for statistical significance. Nevertheless, this experience has provided us with lessons that have optimized our efficacy and safety when performing minimal-access cardiac surgery.

In conclusion, conversion from a partial sternotomy to a full sternotomy occurs infrequently during minimal-access cardiac surgery. Conversion from an upper hemisternotomy for various reasons, most of which are emergencies, such as bleeding, refractory arrhythmias, and ventricular dysfunction, can be associated with serious morbidity and mortality. Conversely, lower hemisternotomy conversions are performed electively because of poor exposure and are not associated with complications. Several technical maneuvers outlined in this article can help reduce the incidence of such conversions. Although minimal-access valve surgery is quite safe in centers with a large body of experience, readers are encouraged to fully understand the complexities involved before undertaking such procedures.

\section{References}

1. Cosgrove DM, Sabik JF. Minimally invasive approach for aortic valve operations. Ann Thorac Surg. 1996;62:596-7.

2. Cohn LH, Adams DH, Couper GC, et al. Minimally invasive cardiac valve surgery improves patient satisfaction whole reducing costs of cardiac valve replacement and repair. Ann Surg. 1997;226:421-8.

3. Mihaljevic T, Cohn LH, Unic D, Aranki SF, Couper GS, Byrne JG. One thousand minimally invasive valve operations. Early and late results. Ann Surg. 2004;240:529-34.

4. Liu J, Sidiropoulos A, Konertz W. Minimally invasive aortic valve replacement (AVR) compared to standard AVR. Eur J Cardiothorac Surg. 1999;16(suppl 2):S80-3.

5. Bonacchi M, Prifti E, Giunti G, Frati G, Sani G. Does ministernotomy improve postoperative outcome in aortic valve operation? A prospective randomized study. Ann Thorac Surg. 2002;73:460-6.

6. Mächler HE, Bergmann P, Anelli-Monti M, et al. Minimally invasive versus conventional aortic valve operations: a prospective study in 120 patients. Ann Thorac Surg. 1999;67:1001-5.

7. Dogan S, Dzemali O, Wimmer-Greinecker G, et al. Minimally invasive versus conventional aortic valve replacement: a prospective randomized trial. J Heart Valve Dis. 2003;12:76-80.

8. Byrne JG, Karavas AN, Adams DH, et al. Partial upper re-sternotomy for aortic valve replacement or re-replacement after previous cardiac surgery. Eur J Cardiothorac Surg. 2000;18:282-6.

9. Greelish JP, Cohn LH, Leacche M, et al. Minimally invasive mitral valve repair suggests earlier operations for mitral valve disease. J Thorac Cardiovasc Surg. 2003;126:365-73.

10. Doty DB, Flores JH, Doty JR. Cardiac valve operations using a partial sternotomy (lower half) technique. J Card Surg. 2000;15:35-42.

11. Gillinov AM, Banbury MK, Cosgrove DM. Hemisternotomy approach for aortic and mitral valve surgery. J Card Surg. 2000;15:15-20.

12. Demirkilic U, Kuralay E, Cingoz F, et al. Brachial artery cannulation facilitates lower ministernotomy cardiac surgery. J Card Surg. 2004; 19:260-3. 